\title{
Treatment of hypergranulation tissue in burn wounds with topical steroid dressings: a case series
}

\author{
Marie Jaeger ${ }^{1, *}$ \\ Moti Harats ${ }^{\prime, *}$ \\ Rachel Kornhaber ${ }^{2}$ \\ Uri Aviv' \\ Amir Zerach' \\ Josef Haik ${ }^{1,3}$
}

'Department of Plastic and Reconstructive Surgery, Sheba Medical Center, Tel Hashomer, Israel; ${ }^{2} \mathrm{School}$ of Health Sciences, Faculty of Health, University of Tasmania, Sydney, NSW, Australia; ${ }^{3}$ Sackler School of Medicine, Tel Aviv University, Tel Aviv, Israel

*These authors contributed equally to this work.
Correspondence: Josef Haik Department of Plastic and Reconstructive Surgery, Sheba Medical Center, Tel Hashomer, Emek HaEla Street I, 5262I, Ramat Gan, Israel

Email josef.haik@gmail.com
This article was published in the following Dove Press journal:

International Medical Case Reports Journal

II August 2016

Number of times this article has been viewed

\begin{abstract}
Hypergranulation tissue (or also known as overgranulation) may negatively influence burn wound healing time and contribute to recurrence of contractures in burn wounds and grafts. Subsequently, the treatment of hypergranulation tissue remains controversial and problematic. In this case series, we aimed to examine the feasibility and document the use of topical hydrocortisone in the treatment of hypergranulation tissue formation resulting from burn wounds. We report five cases where hypergranulation tissue developed following deep dermal/full-thickness burns. Initial burn wound treatment included necrotic tissue debridement, wound cleansing, and Flaminal ${ }^{\circledR}$. All five cases underwent surgical debridement and split-skin grafting. Upon identification of hypergranulation tissue, hydrocortisone acetate $0.25 \%$ was applied topically as usual care for the treatment of hypergranulation tissue. All five patients had deep dermal/ full-thickness burns with a total body surface area ranging from $22 \%$ to $61 \%$ and were aged from 3-41 years. All five cases developed hypergranulation tissue during their admission after debridement and split-thickness skin grafts. All patients showed an improvement in the treated areas with a complete regression of hypergranulation tissue and closure of the burn wounds. No clinically apparent local or systemic side effects of the treatment were observed. Topical hydrocortisone can be utilized as an effective, inexpensive, and noninvasive practical option in the treatment of hypergranulation tissue resulting from burn wounds.
\end{abstract}

Keywords: hypergranulation, overgranulation, proud flesh, burns, hydrocortisone, wound healing

\section{Introduction}

Hypergranulation tissue, often referred to as overgranulation or proud flesh, can be defined as an excess of granulation tissue that fills the wound bed to a greater extent than what is required and goes beyond the height of the surface of the wound resulting in a raised tissue mass. ${ }^{1,2}$ Clinically, it is identified as a red friable, shiny tissue with a soft appearance above the level of the surrounding skin. ${ }^{3}$ Hypergranulation occurs in an array of wounds including burns and venous and pressure ulcers. This tissue prevents migration of epithelial cells across the surface of the wound bed and impedes wound healing. ${ }^{4,5}$ However, the etiology behind the development of hypergranulation tissue is not well understood. ${ }^{6}$ Predisposing factors that have been suggested include healing by secondary intention, ${ }^{7}$ excessive moisture, prolonged inflammation related to infection or residue dressing fibers, ${ }^{8}$ external friction, and the repeated use of occlusive dressings. ${ }^{2}$ Furthermore, a prolonged stimulation of fibroplasia and angiogenesis may result in the formation of hypergranulation tissue that is problematic for wound healing. 5,9 
We estimate that $10 \%-15 \%$ of burn patients admitted to our Unit at the Sheba Medical Center, Tel Hashomer, develop hypergranulation tissue that impedes wound healing. Jewell et al ${ }^{10}$ report a similar figure of $17 \%$ (nine of 52) in their burns study population that developed hypergranulation tissue. Subsequently, those who developed hypergranulation tissue at the site of graft loss experienced a statistically significant increased healing time. ${ }^{10}$ Furthermore, the presence of hypergranulation tissue was a significant independent predictor of time to complete wound healing $\left(R^{2}=0.27 ; P=0.0131\right)$ with a median of 45 days for complete wound healing. ${ }^{10}$

Treatment of hypergranulation tissue includes such methods as dressings that are less occlusive, ${ }^{2}$ surgical excision, chemical cautery with silver nitrate, ${ }^{11,12}$ hypertonic saline, ${ }^{9}$ and laser ablation. ${ }^{7}$ However, these treatments are often not considered uniformly successful. ${ }^{9}$ Topical corticosteroids have been reported to suppress the inflammatory response that contributes to the growth of this tissue..$^{1,9,13,14}$ Other mechanisms of action are the suppression of angiogenesis ${ }^{1,9}$ and the reduction of edema related to stabilization of cell membranes. ${ }^{9}$ However, much of the literature focuses on the treatment of keloid and hypertrophic scars because of the ability of steroids to reduce the excessive fibrous tissue. ${ }^{15}$

To our knowledge, there is limited literature that reports the treatment for hypergranulation tissue formation in burn wounds. Hypergranulation tissue that develops in deep partial and full-thickness burns impedes epithelialization. ${ }^{9}$ Topical steroid application for the treatment of hypergranulation tissue in burn wounds is standard care in our Burn Center in the Sheba Medical Center, Tel Hashomer, Israel. Here, we present the use of topical hydrocortisone in the treatment of hypergranulation tissue formation resulting from burn wounds.

\section{Patients and methods}

Five cases of hypergranulation tissue development in wounds following deep dermal/full-thickness burns were admitted to the Sheba Israel National Burn Center, Tel Hashomer, Israel. All patients identified with the development of hypergranulation emanating from a burn wound over a 3-month period were included in the case series.

In all patients, as per departmental protocol, initial primary burn wound treatment included necrotic tissue debridement, wound cleansing, and Flaminal ${ }^{\circledR}$ (Flen Pharma, Kontich, Belgium). All five of the cases required surgical debridement and split-skin grafting. As soon as hypergranulation tissue was identified, we applied a hydrocortisone acetate $0.25 \%$ lotion diluted in a ratio of $125-250 \mathrm{~mL}$ to $1 \mathrm{~L}$ of sterile water. The solution was not applied directly to the hypergranulation tissue but via gauze pads soaked into the solution, and then sterile bandages were applied to cover the wounds. The application of $125 \mathrm{~mL} / \mathrm{L}$ of solution was used initially, and in the case where there was no significant improvement, a higher concentration solution was applied up to a maximum of $250 \mathrm{~mL} / \mathrm{L}$. After 12 hours, an additional application of the solution was applied utilizing the existing dressings. The dressing was then removed after 12 hours and the whole procedure repeated after wound assessment and cleansing with sterile water and antibacterial solution (chlorhexidine gluconate or iodine solution). During the dressing changes, routine digital photographs were taken with the signed consent of the patient/guardian for the purposes of treatment, teaching and use in academic publications. As this was a retrospective case series report and the procedure described is a well-established standard of care in our Burns Unit at the Sheba Medical Center, the ethics committee of Sheba Medical Center Helsinki Committee, Tel Hashomer, Israel does not require ethics approval to be sought for this case series.

It must be noted that to minimize the systemic effects of steroids absorbed through damaged skin, we intentionally treated one affected area at a time to avoid widespread usage of topical steroids on multiple or extensive burn sites. In addition, we limited the use of topical steroids to a maximum of 4 consecutive days after which we reinitiated standard wound care. The rationale for the 4 consecutive days of topical steroids was based on an internal expert review, our long-term common praxis and experience addressing the hyperinflammatory process, and the fact that the duration is short enough to avoid systemic side effects. If after 4 additional days there was still significant hypergranulation tissue, another course of topical steroids was initiated for up to 4 days. In cases where clinical local infection is suspected, $5 \%$ mafenide acetate suspension is combined with the aforementioned treatment as part of our standard care. However, no burn wound infections were noted in the five reported cases. We believe that the steroids reduce the inflammatory process and allow for wound closure. This is supported by the studies of Guo and DiPietro ${ }^{16}$ and Hofman et $\mathrm{al}^{14}$ who state that although systemic corticosteroids inhibit wound healing, low-dosage topical application for the treatment of chronic wounds has been found to accelerate wound healing, reduce pain and wound exudate, and suppress the formation of hypergranulation tissue. However, careful monitoring of the wound must ensue to prevent the risk of infection with prolonged use. ${ }^{14}$

\section{Results}

Five cases of hypergranulation tissue in patients with deep dermal/full-thickness burns were treated with topical hydrocortisone acetate $0.25 \%$ solution. The age of the patients ranged from 3 to 41 years, and they had a total body surface area 
Table I Patient characteristics

\begin{tabular}{|c|c|c|c|c|c|c|c|}
\hline Patient/case & Age, years & Sex & Burn cause & $\%$ TBSA & Burn depth & $\begin{array}{l}\% \text { of treated } \\
\text { surface area }\end{array}$ & $\begin{array}{l}\text { Number of 4-day } \\
\text { treatments }\end{array}$ \\
\hline I & 41 & M & Electrical burn & 30 & $\begin{array}{l}\text { Deep dermal/full } \\
\text { thickness }\end{array}$ & 0.5 & Once \\
\hline 2 & 24 & $\mathrm{~F}$ & Gas explosion & 33 & $\begin{array}{l}\text { Deep dermal/full } \\
\text { thickness }\end{array}$ & 0.5 & Once \\
\hline 3 & 23 & $M$ & Turpentine burn & 22 & $\begin{array}{l}\text { Deep dermal/full } \\
\text { thickness }\end{array}$ & 1 & Repeated twice \\
\hline 4 & 32 & M & Gas-pipe explosion & 61 & $\begin{array}{l}\text { Deep dermal/full } \\
\text { thickness }\end{array}$ & 5 & Repeated three times \\
\hline 5 & 3 & M & Molotov cocktail & 70 & $\begin{array}{l}\text { Deep dermal/full } \\
\text { thickness }\end{array}$ & 5 & Repeated four times \\
\hline
\end{tabular}

Abbreviations: $F$, female; $M$, male; TBSA, total body surface area.

A

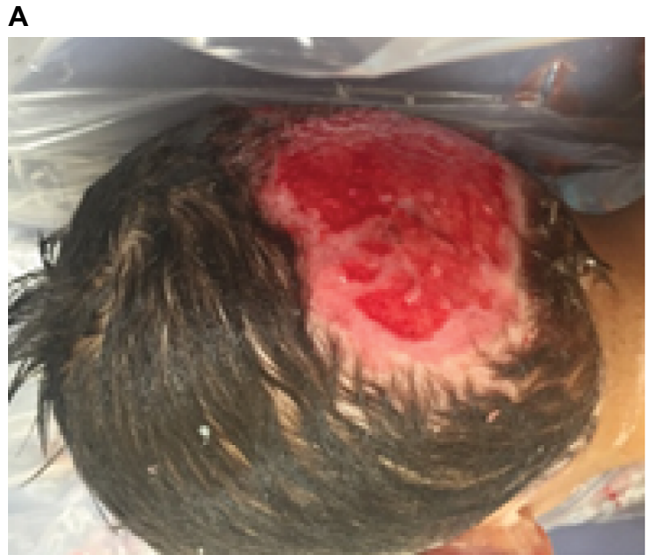

B

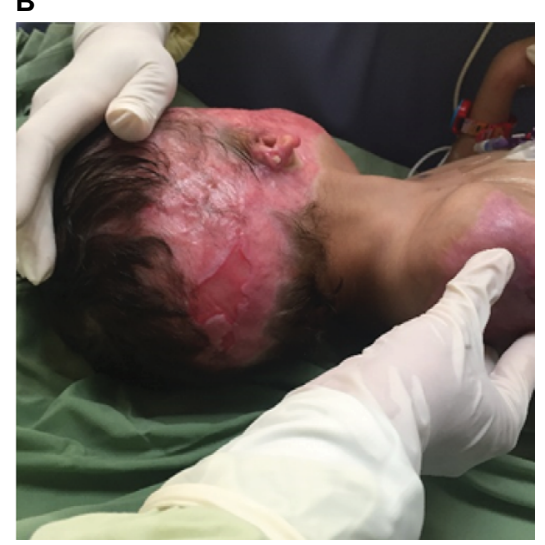

Figure I Case 5.

Notes: (A) Hypergranulation tissue to occipital/parietal region prior to treatment with topical hydrocortisone; (B) 5 weeks after treatment regime with topical hydrocortisone acetate $0.25 \%$ solution.

(TBSA) range of $22 \%-70 \%$ burned, of which two cases were greater than 50\% TBSA. All cases had no significant or relevant medical history. Of the five cases reported, four were male and one was female. The area treated with topical hydrocortisone acetate $0.25 \%$ solution ranged from $0.5 \%$ to $5 \%$ TBSA. Two cases had only one 4-day treatment, one case had the treatment repeated twice, one case had the treatment repeated three times, and the final case had four cycles of the treatment (Table 1).

After treatment of the hypergranulation tissue with the described protocol using hydrocortisone acetate $0.25 \%$ solution, all cases showed a regression of hypergranulation tissue. Figures 1-3(A) clearly demonstrate hypergranulation tissue prior to treatment. Figures 1-3(B) taken after initial treatment show the hypergranulation tissue resolving or resolved. In all cases, none of the patients needed to be regrafted after topical treatment and no areas treated developed clinical signs of infection at the granulation site, showing complete healing of graft sites. Furthermore, no local or systemic side effects were observed from the use of the topical hydrocortisone.
A

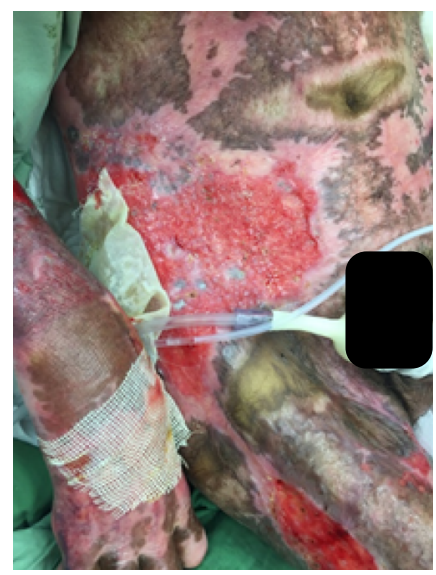

B

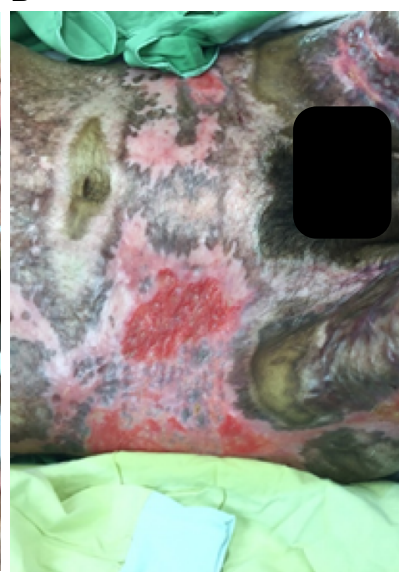

Figure 2 Case 4.

Notes: (A) Hypergranulation tissue to the right iliac region prior to treatment with topical hydrocortisone; (B) I week after treatment regime with topical hydrocortisone acetate $0.25 \%$ solution.

\section{Discussion}

In this case series, we aimed to examine the feasibility and document the use of topical hydrocortisone in the treatment 


\section{A}

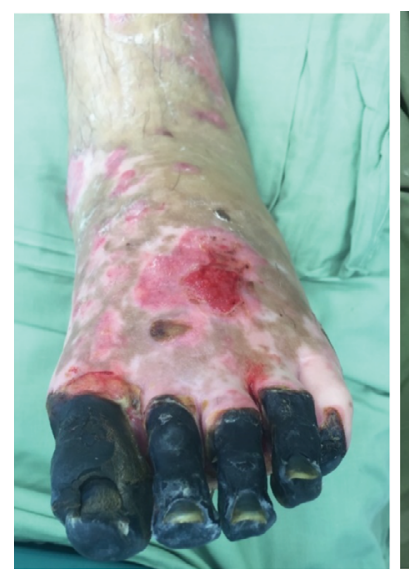

B

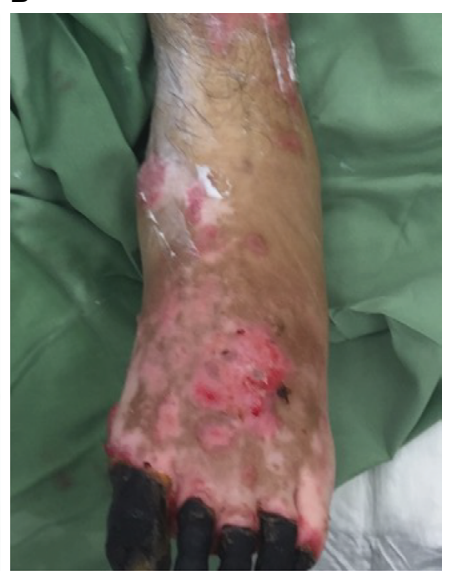

Figure 3 Case I.

Notes: (A) Hypergranulation tissue to the left dorsum prior to treatment with topical hydrocortisone; (B) 3 weeks after treatment regime with topical hydrocortisone acetate $0.25 \%$ solution.

of hypergranulation tissue formation resulting from burn wounds. The use of topical steroids to treat hypergranulation tissue has been reported in the nonburn literature, ${ }^{1,13,14,17} \mathrm{dem}$ onstrating improved wound healing rates. ${ }^{1,13,14}$ Topical steroids have been reported to reduce the inflammatory process that is thought to contribute to the development of problematic hypergranulation tissue..$^{2,13,14}$ However, limited data currently exist concerning the application of topical steroids to wounds displaying a chronic inflammatory response. ${ }^{17}$ Furthermore, we could only find one small study that focused on the use of topical steroids for the treatment of hypergranulation tissue in burns. ${ }^{9}$ Consequently, clinicians remain reluctant to use topical corticosteroids on wounds despite the reduction in pain experienced and stimulation of the wound healing trajectory. ${ }^{14}$ This reluctance has been related to concerns around impairment of wound healing and infection. ${ }^{14}$

For a wound displaying a prolonged inflammation as described in this case series, the use of a topical steroid would be a valid method for the treatment of hypergranulation evident in burn wounds. Shalom and Wong ${ }^{9}$ who used $1 \%$ hydrocortisone twice a day on burns/plastic surgery patients with hypergranulation tissue unresponsive to standard treatment, achieved complete epithelialization of treated areas within 2-4 weeks. Hofman et $\mathrm{al}^{14}$ also found the use of topical steroids (Dermovate, London, UK) effective when applied onto hypergranulated tissue over a 2-week period that resulted in a rapid reduction of wound size and immediate pain relief. McShame and Bellet ${ }^{1}$ reported, similar to a patient in our case series (case 5), hypergranulated tissue to the parietal scalp of a child. After the application of a topical steroid (fluocinonide $0.05 \%$ ointment) twice daily for a 2 -week period, significant improvements were noted and the treatment discontinued.

Examination at 2 months showed complete resolution of the hypergranulated tissue. It is also interesting to note that the scalp surgical wounds appear to have a propensity for the development of hypergranulation tissue. ${ }^{1,7}$ This concurs with our experience suggesting that the scalp may be particularly predisposed to excessive granulation tissue.

In this case series, we describe a noninvasive, inexpensive technique for the management of hypergranulative tissue that was well tolerated by the patients presented. However, this case series is not without its limitations concerning both the design and sample size of five participants. Nonetheless, the aim of this case series was to report and demonstrate our Burn Centre's usual practice in the treatment of hypergranulation tissue. Therefore, we believe that further investigation of the use of topical steroids in the treatment of hypergranulation in burns is warranted.

At the time this case series was reported, there was only one other small study describing the management of hypergranulation tissue in burn patients within the literature. ${ }^{9}$ We strongly believe that the use of topical hydrocortisone is a viable option to achieve hypergranulation regression and wound closure by reducing the granulation tissue in both the burn wound and within the graft. However, qualitative and nonquantitative end points were defined, and further studies are required to validate our findings and to quantify its effect. Importantly, the method reported in this case series needs to be compared to other current treatment modalities in terms of efficacy, toxicity, and cost-effectiveness in the management of hypergranulating burn wounds.

\section{Disclosure}

The authors report no conflicts of interest in this work.

\section{References}

1. McShane D, Bellet J. Treatment of hypergranulation tissue with high potency topical corticosteroids in children. Pediatr Dermatol. 2012; 29(5):675-678.

2. Vuolo J. Hypergranulation: exploring possible management options. Br J Nurs. 2010;19(6):S4, S6-S8.

3. Johnson S. Overcoming the problem of overgranulation in wound care. Br J Community Nurs. 2009;14:S6-S10.

4. Stevens N, ShultzT, Mizner R, Gersh M. Treatment in an outpatient setting for a patient with an infected, surgical wound with hypergranulation tissue. Int J Low Extrem Wounds. 2009;8(1):37-44.

5. Widgerow A, Leak K. Hypergranulation tissue: evolution, control and potential elimination. Wound Healing Southern Africa. 2010;3(2):7-9.

6. Madden K, Paghdal KV, Cohen G. Potassium titanyl phosphate 532 $\mathrm{nm}$ laser for treatment of a chronic nonhealing exophytic wound with hypergranulation tissue. Dermatol Surg. 2011;37(5):716-719.

7. Wang SQ, Goldberg LH. Pulsed dye laser for the treatment of hypergranulation tissue with chronic ulcer in postsurgical defects. $J$ Drugs Dermatol. 2007;6(12):1191-1194.

8. Harris A, Rolstad BS. Hypergranulation tissue: a nontraumatic method of management. Ostomy Wound Manage. 1994;40(5):20-22, 24, 26-30. 
9. Shalom A, Wong L. Treatment of hypertrophic granulation tissue with topical steroids: 141. J Burn Care Res. 2003;24:S113.

10.Jewell L, Guerrero R, Quesada AR, Chan LS, Garner WL. Rate of healing in skin-grafted burn wounds. Plast Reconstr Surg. 2007;120(2):451-456.

11. McGrath J, Schofield O. Treatment of excessive granulation tissue with EMLA cream and 95\% silver-nitrate pencils. Clin Exp Dermatol. 1990; 15(6):468.

12. Borkowski S. G tube care: managing hypergranulation tissue. Nursing. 2005;35(8):24.

13. Mandrea E. Topical diflorasone ointment for treatment of recalcitrant, excessive granulation tissue. Dermatol Surg. 1998;24(12):1409-1410.
14. Hofman D, Moore K, Cooper R, Eagle M, Cooper S. Use of topical corticosteroids on chronic leg ulcers. J Wound Care. 2007;16(5): 227-230.

15. Moio M, Mataro I, Accardo G, Canta L, Schonauer F. Treatment of hypergranulation tissue with intralesional injection of corticosteroids: preliminary results. J Plast Reconstr Aesthet Surg. 2014;67(6):e167-e168.

16. Guo S, DiPietro LA. Factors affecting wound healing. J Dent Res. 2010; 89(3):219-229.

17. Bosanquet DC, Rangaraj A, Richards AJ, Riddell A, Saravolac VM, Harding KG. Topical steroids for chronic wounds displaying abnormal inflammation. Ann R Coll Surg Engl. 2013;95(4):291-296.

\section{Publish your work in this journal}

The International Medical Case Reports Journal is an international, peer-reviewed open-access journal publishing original case reports from all medical specialties. Previously unpublished medical posters are also accepted relating to any area of clinical or preclinical science. Submissions should not normally exceed 2,000 words or

Submit your manuscript here: https://www.dovepress.com/international-medical-case-reports-journal-journal

4 published pages including figures, diagrams and references. The manuscript management system is completely online and includes a very quick and fair peer-review system, which is all easy to use. Visit http://www.dovepress.com/testimonials.php to read real quotes from published authors. 